large as a Lima bean. (Fig. 3.) The sclera over this bean. I diagnosed glioma, and advised enucleation. region is thin, showing the choroid through. The But the parents wished me to save the ball, if possigrowth or tumor, he says, has only been coming two ble without damage to the other eye. I insisted that months, and is now growing fast, increasing every there was danger of sympathetic ophthalmia of the day-probably sarcoma. December 17 , with hypo- fellow-eye, but no immediate danger. Not getting dermic syringe I injected the tumor with methyl- their consent to operate, I commenced the use of violet solution, 1 to 1,000 , gtts. $v$. There was a methyl-violet, 1 to 1,000 , dropped into the eye; this watery fluid escaped under the conjunctiva, pro- relieved pain and soreness of the eye. I prescribed ducing some chemosis. December 18, tumor re- a bottle of methyl-violet, to be taken home with them duced and pain gone. December 19 , no pain and less (in the country) and its use continued. The child tension. December 20, no pain, methyl-violet 1 to has been back to me several times since, and there 1,000 dropped in the eye once a day; this treat- has been no pain or soreness since the use of methylment was contimued for one week from the time of violet, and at the last visit the tumor seemed to be first injection. Then a fresh solution of 1 to 1,000 , smaller.

gtts. v, was injected into the vitreous chamber. The injection created some soreness of the ball, but no pain followed either injection. Care was taken that the needle used for the injection was sharp, the instrument aseptic and the fluid fresh. December 26, methyl-violet pomade was applied instead of fluid. Some pain followed this application. The fluid was resumed, 1 to $3 \mathrm{gtts}$. dropped in to the eye each day. Since then up to the present date there has been no pain or soreness; the eye feels comfortable, and the patient says it does not seem so large under the lid; tension is reduced to the normal. The ciliary injection, which was quite prominent when first examined, is nearly gone, and the tumor is certainly one-third smaller than at the first examination. At the last examination I noticed a slight retinal reflex of this eye, showing that the turbid vitreous was clearing; and the patient mentioned that he was now able to discern objects passed before the eye, something he had not been able to do before for several years. The appended letter shows the permanency of the good effect of the treatment:

IINDSBURY, KAx., January 27, 1892.

Dr. F. B. Tiffany, Kaxsas City, Mo.

Dear sir:-As the tumor of $m y$ eye is about the same as it was when I left Kansas City, I thought about writing to you for advice. Do you think it would be advisable to inject any more medicine? Do you think it would reduce the tumor by injecting any more? If so, please let me know by return mail, because I can go down with a carload of cattle that is going to be shipped from this place next week so it will cost me nothing to go down if I know it in time I have had no pain whatever in the eye since I came home. Respectfully yours, Gust Nordiand.

The first injection was made the 17 th of December, 1891 , and the second the 23d of December, 1891.

As the eye was quiet and evidently improving, I have not yet made the third injection, and up to the present writing (March 5) the eye still continues to improve.

Case 3.-M. Q., age 6 years, Quick City, Mo., came August 6, 1891. History as obtained from the father: About four weeks ago, the child stuck a table fork in his left eye, at the lower and inner third of the eye (ciliary margin of the iris).

Diagnosis.- Luxation and traumatic cataract of the lens. Vision, count fingers. This patient was brought during my absence from the city. My assistant, Dr. Merriman, made the above diagnosis. The parents then took the child to another oculist, who diagnosed suppuration of globe, and advised immediate removal of the eyeball. Some days later the child was brought back to my office, when an examination revealed a bright fleshy-looking body rising from the inferior ciliary region, with blood-vessels unting over it. The body was as large as a Lima drug.

Since methyl-violet has such an extraordinary penetrability, and canses. little or no irritability if used in the strength of 1 to 1,000 , and has for its predilection the nuclei of cells and bacilli, it seems especially indicated in deep-seated affections of the eye, especially those of the uveal tract.

\title{
A PROPER SUBJECT FOR PUBLIC HEALTH.
} BY E. CHENERY, M.D.

As I have been in dispensary work, I have been surprised at the prevalence of the itch, particularly among the Italians, and others of the lower foreign people who crowd together in uncleanliness, and then go through the community hawking their trinkets. Repeatedly I have seen persons covered from head to foot with this infectious disease, and on inquiry found that they were peddlars, going from house to house with cloth and other articles, which the people handle. Further inquiries have elicited the fact that they have had the eruption several years, and that others of the same dens are in a like condition. Now it is almost useless for a private or dispensary physician to attempt to eradicate the disease, even from one of them, to say nothing of exterminating the pest from the mass of filthy rags which they wear or amid which they sleep. Such dens of infection are far more worthy of public attention than many subjects of less practical importance. I have wished I could send word to the Board of Health, and have such people and such quarters taken into vigorous hands. As it is, I am afraid that our city board has reversed the old adage-attending to the dollars and leaving the cents to take care of themselves. Forty years ago a teacher of skin diseases came to the office of $\mathrm{my}$ preceptor, who had the oversight of large dispensary work at the north end, desiring that we would let him know of any case of scabies, for he said it was one of the rarest diseases in the city. According to my experience in that part of the city, he could not say that to-day. Boston may be an exception to other cities.

Electric Baths for the Treatment of Syphilis. -At the General Hospital of Vienna iI. Kronfeld has found that the employment of electric baths causes a more complete and efficacious absorption of mercury than other methods of administering the drug. Nore mercury is eliminated in the urine; no. albuminuria is caused; polyuria is rare. The patients are stated to be cured in from two to four weeks after having taken from ten to twenty-five baths. Symptoms of mercurial poisoning must be looked out for in this as in other modes of using the 